\title{
BUDAYA HUKUM ANTI KORUPSI PADA WARGA BINAAN LAPAS KLAS II A AMBON
}

\author{
Erwin Ubwarin ${ }^{1}$, Jacob Hattu ${ }^{2}$, Wilshen Leatemia ${ }^{3}$ \\ ${ }^{1,2,3)}$ Program Studi Ilmu Hukum, Fakultas Hukum, Universitas Pattimura \\ e-mail: eubwarin@gmail.com
}

\begin{abstract}
Abstrak
Salah satu tri dharma perguruan tinggi adalah pengabdian kepada masyarakat. Kami melakukan pengabdian kepada masyarakat pada Lembaga Pemasyarakatan Klas II A Ambon, kami memakai metode jigsaw untuk melakukan metode pembelajaraan agar peserta lebih muda memahami materi yang kami sampaikan, awalnya kami membagikan 3 (tiga) kali kuesioner pada saat sebelum kegiatan penyuluhan setelah kegiatan penyuluhan dan pada selesai kegiatan role play oleh tim yang mempersentasikan materinnya. Penegakan hukum tindak pidana korupsi dimulai dari pencegahan. Kami berharap setelah para warga binaan ini keluar dari Lembaga Pemasyarakatan Klas II A Ambon, mereka bisa menjadi agent of change untuk membawah perubahan di dalam Lembaga Pemasyarakatan maupun di masyarakat luas karena telah paham tentang pentingnya budaya hukum anti korupsi
\end{abstract}

Kata kunci: Anti Korupsi, Warga Binaan, Budaya.

\begin{abstract}
One form of tri dharma tertiary institution is community service. We serve the community at the Ambon Class A Correctional Institution II, we use the jigsaw method to do the learning method so that the younger participants understand the material that we submit, initially we distribute 3 (three) questionnaires before the extension activities after the extension activities and at finished the role play activity by the team that presented the material. Law enforcement starts with prevention of corruption. We hope that after these fostered citizens leave the Ambon Class A Correctional Institution, they can become agents of change to bring about changes within the Penitentiary and the wider community because they understand the importance of the anticorruption legal culture.
\end{abstract}

Keywords: Anti-Corruption, Guided Residents, Culture.

\section{PENDAHULUAN}

Pada Maret 2018, jumlah penduduk miskin di Maluku 18,12 persen (Ubwarin, E., Gasperz, N., \& Sisinaru, S. 2019), salah satu penyebab kemiskinan adalah masih banyak pejabat yang terlibat dalam kasus korupsi, untuk itu perlu adanya budaya hukum yang baik di dalam masyarakat Maluku. Friedmann, mengatakan sistem hukum terdiri atas struktur hukum (legal structure), substansi/materi hukum (legal substance), dan budaya hukum (legal culture) (Marbun, R. 2014). Barda Nawawi Arief menyebutkan bahwa tidak ada artinya hukum pidana (KUHP) diganti/diperbaharui, apabila tidak dipersiapkan atau disertai dengan perubahan ilmu hukum pidananya. Criminal law reform atau legal substance reform harus disertai pula dengan pembaharuan ilmu pengetahuan tentang hukum pidananya (legal/criminal science reform). Hal tersebut harus disertai pula dengan pembaharuan budaya hukum masyarakat (legal culture reform) dan pembaharuan struktur atau perangkat hukumnya (legal structure reform) (Arief, B. N. 2014). Itu berati selain pengaturan materi hukum, dalam peraturan perundang-undangan, struktur hukum yaitu aparat penegak hukum, dan tidak kalah pentingnya adalah budaya hukum. Penulis mengatakan walaupun substansi hukum yang tidak baik namun dilakukan oleh struktur hukum yang baik akan menimbulkan budaya hukum yang baik.

Budaya hukum bukan hanya harus tumbuh di masyarakat diluar Lembaga Pemasyarakatan, namun didalam masyarakat pemasyarakatan juga perlu tumbuh budaya hukum yaitu budaya 
hukum untuk narapidana. Timbul pertanyaan kenapa pengabidannya harus narapidana karena didalam lembaga pemasyarakatan narapidana juga punya hak untuk mendapatkan pendidikan, adapun hak-hak narapidana sebagai berikut :

1) melakukan ibadah sesuai dengan agama atau kepercayaannya;

2) mendapat perawatan, baik perawatan rohani maupun jasmani;

3) mendapatkan pendidikan dan pengajaran;

4) mendapatkan pelayanan kesehatan dan makanan yang layak;

5) menyampaikan keluhan;

6) mendapatkan bahan bacaan dan mengikuti siaran media massa lainnya yang tidak dilarang;

7) mendapatkan upah atau premi atas pekerjaan yang dilakukan;

8) menerima kunjungan keluarga, penasihat hukum, atau orang tertentu lainnya;

9) mendapatkan pengurangan masa pidana (remisi);

10) mendapatkan kesempatan berasimilasi termasuk cuti mengunjungi keluarga;

11) mendapatkan pembebasan bersyarat;

12) mendapatkan cuti menjelang bebas; dan

13) Institute for Criminal Justice Reform (Ubwarin, E., \& Salamor, Y. B. 2018).

Pada point ke 3 disebutkan bahwa narapidana berhak mendapatkan pendidikan dan pengajaran, untuk itu tujuan pengabdian kepada masyarakat ini bertujuan untuk memberikan pemahaman tentang budaya anti korupsi bagi masyarakat.

\section{METODE}

Metode pengabdian masyarakat yang digunakan adalah memberikan penyuluhan yang bertujuan meningkatkan pemahaman peserta namun memakai metode Jigsaw, dan bermain peran atau Role Play, kenapa memakai metode jigsaw karena Jigsaw didesain untuk meningkatkan rasa tanggung jawab peserta terhadap pembelajarannya sendiri dan pembelajaran orang lain. Peserta tidak hanya mempelajari materi yang diberikan, tetapi mereka harus siap memberikan dan mengajarkan materi tersebut pada anggota kelompok yang lain. Dengan demikian, siswa saling tergantung satu dengan yang lain dan harus bekerja sama secara kooperatif untuk mempelajari, Amargawati (Ambar Dwi. 2017).

\section{HASIL DAN PEMBAHASAN}

Pola kebijakan dalam pembinaan Warga Binaan Pemasyarakatan berdasarkan Sistem Pemasyarakatan telah sesuai dengan doktrin ilmu Penologi, yaitu rehabilitasi dan reintegrasi sosial yang menitik beratkan pada treatment approach. Pola rehabilitasi dan reintegrasi sosial lebih maju selangkah dari pola resosialisasi, karena bernuansa keseimbangan dalam memberikan pengayoman bagi kepentingan masyarakat maupun Warga Binaan Pemasyarakatan itu sendiri. Sistem Pemasyarakatan ideal maupun konstitusional dapat dikatakan telah memenuhi tuntutan reformasi yang menjunjung tinggi demokrasi yang sarat dengan muatan hak asasi manusia (HAM). Pendidikan Budaya anti korupsi ini penting bagi narapidana yang merupakan warga binaan. Korupsi adalah musuh kita berasama, kita semua mengetahui bahwa bahaya laten korupsi menghantui masyarakat. Pengertian Korupsi oleh Hamza dalam Erwin Ubwarin, Secara etimologis, korupsi berasal dari bahasa Latin yaitu corruption atau corruptus, dan istilah bahasa Latin yang lebih tua dipakai istilah corumpere. Dari bahasa Latin, seperti bahasa bangsa-bangsa di Eropa seperti Inggris: corruption, Prancis: corruption, dan Belanda:corruptive dan korruptie, yang kemudian turun kedalam bahasa Indonesia menjadi Korupsi. Arti harafiah dari kata itu ialah kebusukan, keburukan, kebejatan, ketidak jujuran, dapat disuap, tidak bermoral, penyimpangan dari kesucian (Ubwarin, E., \& Salamor, Y. B. 2018).

Penanganan korupsi harus dilakukan dengan luar biasa, pelanggulangannya tidak bisa hanya dilakukan pada saat penindakan namun juga pada saat pencegahaan (Patty, J. 2019). Penanggulangan tindak pidana korupsi yang paling pertama adalah pencegahaan, pengabdian 
masyarakat yang dilakukan di Lembaga Pemasyarakatan Klas II A Ambon merupakan bentuk dari pencegahan.

Kegiatan ini kami mulai dengan melakukan komunikasi dengan pihak lapas pada ahir tahun 2019, Ibu Serworwora yang mewakili Kepala Lapas Klas II A Ambon, menyambut baik kegiatan ini, kami melakukan di Lapas Klas II A, Ibu Serworwora memilih 50 (lima puluh) narapidana yang dianggap berperikaku baik dan sudah hampir waktu untuk menjalani asimilasi. Kegitan. Kemudian berdasaran bagikan kuesioner kepada mereka. Kami menganalisis hasil kuesioner dan kusioner setalah pemberian materi untuk menentukan mana yang masuk kedalam kelompok ahli dan mana yang masuk dalam kelompok asal.

Para anggota warga binaan dari tim-tim yang berbeda dengan topik yang sama bertemu untuk diskusi saling membantu satu sama lain tentang topik pembelajaran yang ditugaskan kepada mereka. Kemudian, warga binaan tersebut kembali pada tim/kelompok asal untuk menjelaskan kepada anggota kelompok yang lain tentang hal yang telah dipelajari sebelumnya pada pertemuan tim ahli. Pada model pembelajaran kooperatif tipe jigsaw, terdapat "kelompok asal dan kelompok ahli". Kelompok asal, yaitu kelompok induk warga binaan yang beranggotakan warga binaan dengan kemampuan, asal, dan latar belakang keluarga yang beragam. Kelompok asal merupakan gabungan dari beberapa ahli. Sementara itu, kelompok ahli yaitu kelompok warga binaan yang terdiri dari anggota kelompok asal yang berbeda yang ditugaskan untuk mempelajari dan mendalami topik tertentu dan menyelesaikan tugas-tugas yang berhubungan dengan topiknya untuk kemudian dijelaskan kepada kelompok asal.

Tiap kelompok asal kemudian mempresentasikan materi yang telah dibuat dalam bentuk role play, mereka tertawa dan pada evaluasi tahap akhir dari semua peserta paham akan budaya korupsi.

\section{SIMPULAN}

Pencegahaan tindak korupsi harus dimulai dari masyarkat, warga binaan merupakan salah satu target pencegahan, karena didalam Lembaga pemasyarakatan juga diberikan pengajaraan dan pendidikan kepada warga binaan, materi yang kami sampaikan dalam bentuk jigsaw.

\section{SARAN}

Kami berharap materi yang telah disampaikan dapat dilaksanakan dalam kehidupan di dalam Lapas maupu nantinya di dalam masyarakat, dan dapat memberikan materi untuk lapisan masyarakat yang lainnya.

\section{UCAPAN TERIMA KASIH}

Fakultas Hukum Universitas Pattimura

Lembaga Penelitian dan Pengabdian Universitas Pattimura

Lembaga Pemasyarakatan Klas II A Ambon

\section{DAFTAR PUSTAKA}

Amargawati, A. D. (2017). Penerapan Model Pembelajaran Jigsaw untuk Meningkatkan Hasil Belajar Matematika pada Siswa Kelas VII SMPN 1 Karangploso. Cendekia, 11(1): 13-30.

Arief, B. N. (2014). Beberapa Aspek Kebijakan Penegakan dan Pengembangan Hukum Pidana,. Bandung: Citra Aditya Bakti.

Marbun, R. (2014). Grand Design Poli_k Hukum Pidana dan Sistem Hukum Pidana Indonesia. Padjadjaran Jurnal Ilmu Hukum, 1 (3). 559-570. 
Patty, J. (2020). jmp Pelarangan Mantan Terpidana Korupsi Menjadi Calon Kepala Daerah Agar Menimbulkan Efek Jera. JURNAL BELO , 5(1), 1-9.

Ubwarin, E., \& Salamor, Y. B. (2017 Vol. 2, No. 1). Mekanisme Pengembalian Kerugian Negara oleh Terpidana yang Meninggal Dunia Pasca Putusan Mahkamah Konstitusi Nomor 25/PUU-XIV/2016. Jurnal Muara Ilmu Sosial, Humaniora, dan Seni , 51-57.

Ubwarin, E., \& Salamor, Y. B. ( 2018). Penanggulangan Kelebihan Penghuni Lembaga Pemasyarakatan di Wilayah Maluku. Jurnal Muara Universitas Tarumanagara , 1 (2). 109117.

Ubwarin, E., Gasperz, N., \& Sisinaru, S. (2019). Community Empowerment through The Hygiene and Competitive Production of Balobo Salted Fish. MITRA: Jurnal Pemberdayaan Masyarakat , 3 (2). 141-150. 